\title{
Paramedics's perspectives on hospital transfers of nursing home residents - a qualitative focus group study
}

\section{Alexandra Pulst ( $\square$ a.pulst@uni-bremen.de)}

Universitat Bremen https://orcid.org/0000-0002-7997-6668

\section{Alexander Maximilian Fassmer}

Carl von Ossietzky Universitat Oldenburg

\section{Falk Hoffmann}

Carl von Ossietzky Universitat Oldenburg Bibliotheks- und Informationssystem

\section{Guido Schmiemann}

Universitat Bremen

\section{Research article}

Keywords: nursing home residents, hospitalization, hospital admission, patient transfer, referral, transition, emergency department, emergency medical services, decision making, advance care planning

Posted Date: November 6th, 2019

DOI: https://doi.org/10.21203/rs.2.16936/v1

License: (c) (i) This work is licensed under a Creative Commons Attribution 4.0 International License. Read Full License 


\section{Abstract}

Background: Emergency department (ED) visits and hospital admissions are common among nursing home residents (NHRs). These transfers are often considered avoidable and can have negative effects on residents' health status. Emergency medical services (EMS) are an important linking profession between nursing homes (NHs) and hospitals and responsible for transports. So far, little is known about the perspectives of paramedics in this context. The aim of this qualitative study is to explore how paramedics experience hospital transfer process of NHRs and how hospitalizations could be avoided from their point of view. Methods: A qualitative study with three focus groups was conducted with paramedics. The focus groups followed a semi-structured question guide focusing on issues during transfer process, avoidable hospital transfers and potential interventions which might reduce transfers from NHs. Discussions were audio recorded and transcribed verbatim. Data were analyzed by content analysis using the software MAXQDA. Results: In total, 18 paramedics (mean age: 33 years, male $n=14$ ) participated in the focus groups. Paramedics mainly reported about perceived structural reasons (e.g. understaffing or lack of time) in NHs which led to initiation of an emergency call. Paramedics were often faced with poorly organized handovers because of lacking or incomplete information. In many cases, nursing staff was perceived as insufficiently qualified and not well-prepared regarding health status of NHRs. Throughout transfer process, the behavior of all involved professional groups (dispatcher/ambulance control center, nurses, physicians and paramedics) was influenced by legal uncertainties. Paramedics rated hospital transfers as avoidable in case of urinary catheter complications, exsiccosis/infections and partially in case of falls. Emergency standards in NHs, trainings for nursing staff, improvement of working conditions and legal conditions were discussed as potential interventions which could reduce hospital transfers of NHRs. Conclusion: Paramedics are faced with complex issues when transporting a NHR to hospital. According to their point of view staff shortage and legal uncertainties play a relevant role in transfer decisions. Interventions reducing (avoidable) hospital transfers of NHRs have to take these factors into account. Keywords: nursing home residents, hospitalization, hospital admission, patient transfer, referral, transition, emergency department, emergency medical services, decision making, advance care planning

\section{Background}

Nursing home residents (NHRs) represent a frail und vulnerable population group suffering from multimorbidity $[1,2]$. Changes or deteriorations in residents' health status often result in hospital treatment: In several studies prevalence of hospital transfers from nursing homes (NHs) ranges from $6.8 \%$ to $45.7 \%$ for various time periods of follow-up [3]. In Germany, hospitalization rates of NHRs seemed to be higher than in other countries [4]. The risk of hospital admissions increases in the last months of life [5-10].

Health problems of NHRs are usually managed by a general practitioner (GP) or other medical specialists. In contrast to other countries, physicians in Germany are not directly employed by NHs. Symptoms which occur in the evening, night or at weekend can be managed by outpatient out-of-hours medical care 
(OOHC). In Germany, this service is provided by the associations of statutory health insurance (SHI) physicians and can be reached via a central telephone number (call 116 117). The $00 \mathrm{HC}$ provides telephone support, walk in clinic as well as home visits [11]. In contrast to the $\mathrm{OOHC}$, the emergency medical services (EMS) (call 112) is primary responsible for initial treatment and transport of patients with urgent and life-threatening conditions [12]. Both care systems are organized independently from each other. However, in the last years interventions performed by paramedics and emergency physicians increased in NHs $[13,14]$. In Germany, every twelfth EMS transport (8.3\%) each year is requested to NHs [15]. Hospital transfers of NHRs were often initiated by nurses without involvement of a physician [16]. Due to demographic changes, EMS utilization might increase in future [17] contributing to the problem of already overcrowding emergency departments (EDs) [18].

Several studies indicated that many ED visits and hospital admissions from NHRs are inappropriate or avoidable [19], the proportions range between $1.7 \%$ to $67 \%$ depending on definition and study design [2023]. Hospital discharges of NHRs can lead to - often preventable - adverse events and might increase the risk of iatrogenic diseases and delirium $[24,25]$. Most studies in this research area are based on analysis of ambulatory care sensitive (ACS) conditions [26-28] or represent the perspectives of GPs [2931] or nursing staff [32]. Research about the perspective of paramedics who are daily involved in hospital transfer process of NHRs scarce. The authors of these studies $[33,34]$ described mainly insufficient documentation of resident's information and issues to understand and consider resident's wishes. So far, there is also no study existing which determined these paramedics' experiences in the context of health care conditions in Germany.

In the German project 'Hospitalisierung und Notaufnahmebesuche von Pflegeheimbewohnern'(HOMERN) we examined health care of NHRs with special focus on hospital transfers. The project used several data sources and methods like SHI claims data, questionnaire surveys with physicians and nursing managers and cross-sectional data of NHs in Germany [35] to analyze reasons for hospitalization. To gain further perspectives on this topic, this study explored how paramedics experience transfer process of NHRs and where they perceive need for action to reduce (unnecessary) hospital transfers from NHs.

\section{Methods}

This study used a qualitative approach to answer the research question. We chose focus groups to gain new insights into a complex topic gathering in-depth data of this professional group regarding transfer process. During planning the focus groups, we followed methodological guidelines [36-38] on recruiting, moderation and conducting. Ethical approval for this study was given by the ethics committee of the medical association in Bremen, Germany (application number 613/A).

This study followed the consolidated criteria for reporting qualitative research (COREQ) [39].

\section{Recruitment and study population}


Snowball sampling was applied to recruit participants for the focus groups. We contacted regional EMS organizations and used existing cooperation to $\mathrm{NHs}$, personal and professional contacts, their networks, and social media to identify potentially interested persons. An invitation letter containing purpose of the study, date and place of focus groups and contact information was sent via email. Participants were included if they 1) were emergency medical technicians (EMTs) ("Rettungssanitäter"), paramedics ("Rettungsassistenten") or emergency paramedics ("Notfallsanitäter") (paramedics with higher level of certification and extended competences since 2014 in Germany), 2) had experience with emergency care of NHRs and 3) worked in Bremen or surrounding regions of Lower Saxony in Germany. Because EMS in Germany are structured and organized differently, we intended to address persons of different EMS sponsorships, regions (rural, semiurban, urban) and levels of working experience to reach a sample of maximal variation. Persons willing to participate received a confirmation letter thanking for interest and providing additional information about planning. Participants were reminded few days before via telephone. Recruitment was coordinated by AP and GS who also participated in the focus groups.

\section{Focus group process}

We conducted the focus groups with paramedics between April and June 2019 in Bremen, Germany. The aim was to identify paramedics' experiences in the cooperation with $\mathrm{NHs}$ and possible needs for action to reduce potentially avoidable hospital transfers of NHRs. As recommended for focus groups [37], we planned at least three group discussions. The discussions took place in rooms of the Association of SHI Physicians in Bremen. The discussions lasted between 112 and 125 minutes and were audio-recorded. Each group was moderated by AP (researcher, female) and was assisted by GS (researcher, private lecturer and GP, male) and a student worker (female) who took notes and documented the session. Both researchers (AP, GS) had backgrounds in health services and nursing research for several years and were engaged in the HOMERN project.

We used a semi-structured question guide (see Additional file I) to structure the discussions. The guide was based on the study objectives and discussed with project group members before. We followed the guidelines of Krueger (1997) to develop appropriate open-ended questions [40]. The interview guide was pilot tested previously with one paramedic. Unclear and double questions were then modified. After the first focus group, the guide was slightly modified to improve data content without changing consistency.

Before focus group, the participants were informed about purposive/reason of the study, researchers' interest in the research topic and information that participation was voluntary, and responses would be anonymized. In addition, a short questionnaire about some sociodemographic data (sex, age, professional group, and years of working experience) was completed. Participants gave written informed consent to the study before sessions started.

The discussions started with a brief introduction of each participant about their general experience with $\mathrm{NHs}$ in their daily work. Participants were requested to take notes on moderation cards which were clustered on a flipchart. Headed by chronology of transfer process, following topics were addressed: Initiation and reasons of emergency call ("112"), experiences at arrival in NHs, and influencing factors on 
transfer process (e.g. advance directives (ADs), role of relatives). Across these topics we focused mainly on three exploratory questions: "Which experiences do paramedics perceive in cooperation with NHs?", "How would paramedics define an 'avoidable' hospital transfer among NHRs?" and "Which interventions would paramedics suggest to reduce hospital transfers?" (see Additional file I). After discussion of all topics, participants were asked if they wanted to mention any additional issues. Key themes were summarized at the end of the sessions by both researchers. After the third focus group we reached data saturation, additional data did not gain any further information or new understandings.

\section{Additional file l: Focus group question guide}

Each participant received a financial allowance of 50.00 euro for participation (compensation for time and transport) in the study. The audio recordings were transcribed by professional transcriptionist office, anonymized and added by notes which were documented during focus group discussions.

We used qualitative content analysis [41] to identify common perspectives of paramedics with transfer process of NHRs. Analysis was oriented by our focus group guide and was further complemented by new information which emerged during discussion. We therefore used a mix of deductive and inductive approach. Firstly, two researchers (AP and AF) independently read transcripts several times to get an overview and get familiar with data (preparation phase). AP used open coding by writing notes and headings while reading transcripts until all aspects of content were described. A coding sheet was developed to group and order headings into categories and subcategories. Coding sheet and coding results were controlled and reviewed by AF. Disagreements were discussed between AP and AF until consensus was reached. The transcripts were then analyzed again (organizing phase). We followed chronology of transfer process to structure data analysis (reporting). The consensus coding process was supported by the software MAXQDA Analytics Pro 2018.

Five main themes emerged that captured experiences of paramedics widely (see Fig. 1). To cross-check our findings, we summarized the results of all three groups and returned them to the participants via email. Participants were invited to comment if all relevant contents were covered by the main themes and if they would modify themes (participant validation). After two weeks, 5 of 18 participants responded to the request and gave feedback via email. As a result, no major revisions emerged.

\section{Results}

\section{Characteristics of participants}

The total sample consisted of $\mathrm{N}=18$ participants ( $\mathrm{n}=14$ male; $\mathrm{n}=4$ female) across three focus groups. They were aged between 21 and 55 years (mean: 33 years). $\mathrm{N}=4$ participants worked as EMTs, $\mathrm{n}=4$ were paramedics and $n=10$ were emergency paramedics. Working experience ranged between 1 and 29 years (mean: 10 years). 11 of 18 (61\%) participants worked in urban areas ( $>100,000$ residents) and 7 of 18 
(39\%) in semi-urban (> 20,000- $\leq 100,000$ residents) or rural areas ( $\leq 20,000$ residents) in the region around the city Bremen in Germany. A detailed description of focus group members is illustrated in Tab. 1

\section{Tab. 1: Description of focus group members}

EMT: emergency medical technicians

Five themes emerged during focus groups and could be classified in chronological order of transfer process: "initiation of emergency call", "arrival at NHs", "transport decision and influencing factors", "avoidable hospital transfers" and "potential interventions to reduce hospital transfers from NHs" (see Fig. 1).

\section{Fig. 1: Main themes in hospital transfer process: Overview of categories and subcategories}

$A D$ : advance directive, ED: emergency department, $N H$ : nursing home

\section{Initiation of emergency call}

\section{$\underline{\text { Structural reasons }}$}

When an emergency call ("112") was initiated, the decision to send out the EMS was taken by the dispatcher in the ambulance control center. Paramedics reported that dispatchers were personally liable for all decisions they made. Even though an emergency call was initiated because of non-serious symptoms, the dispatcher would always send out an ambulance to be on the safe side. Already at this point of transfer process, unnecessary hospital transfers may be identified but could not be avoided:

[...] it is incredibly difficult for the dispatchers on the phone to decide [...] what is going on on-site [...] it is acute, it is not acute [...]. It is more difficult to find out if it's just this or if medical assessment is needed. $(B 5, F G 1)$

In Germany two kinds of transports can be differed: a) patient transport for planned or non-urgent cases which can be initiated after medical order by a physician and b) emergency rescue transports which can be carried out without medical order. Even though a large number of NHRs could be transferred to hospital in form of a planned patient transport, this does not happen:

And when the nurses call us and say: "We need a transport here" and there was no physician on-site and did not fill out any transport order before, then the dispatcher had to send out an ambulance [...]. He does not have to say: "You do not get an ambulance, organize the transport order firstly" or something like this. 
Instead, they are rigorously sending out an ambulance. And then, we are standing there again (laughing). (B2, FG2)

Paramedics observed difficult working conditions in NHs. In their point of view, staff shortage and lack of time were main reasons for initiation of an emergency call:

There is too few staff in the NHs, they cannot manage their work at all. Actually, they only try to handle these things which are very very important, everything else is actually not possible anymore. $(B 3, F G 2)$

I think that if we say: "Please monitor the patient", they know that they can't monitor the patient adequately because they do not have time for it. (B5, FG2)

As a result of these working conditions nurses would not be able to manage care of NHRs adequately. Especially at night, at weekend and before holidays paramedics had the impression that nurses tried to get rid of some residents:

It feels like if it is easy for the staff to get rid off the residents, they simply cannot manage it anymore. Something I could understand. They have too much patients there. (B2, FG2)

Nursing staff-related reasons

On the one hand, paramedics felt sorry for nursing staffs' working conditions and admitted that there was no personal blame on them. On the other hand, they still criticized nurses' behavior of calling the EMS. Paramedics traced this back on insufficient professional nursing expertise:

[...] there are often only bagatelles why we are called. This can be just a little infection or fever and then they are like overstrained. And they do not know what to do, because they simply do not have the qualification [...]. (B1,FG3)

[...] well I think, they should know the all medication prescribed and their indication when they are giving them their residents every day. This would make life easier. (B2,FG1)

In addition, paramedics perceived nurses' willingness to assume responsibility as poor. They would often prefer the EMS instead of managing the problem firstly in $\mathrm{NHs}$ and by themselves:

[...] well, somehow this is the greatest issue and it occurs actually during every drive in NHs. "I just want to be on the safe side." [...] For example, there is a big discussion in one $\mathrm{NH}$, they send every patient to the hospital who fell. Because he could have a brain haemorrhage [...]. And if we discuss with them endlessly, they insist on a transfer. (B2,FG1)

Paramedics questioned this behavior especially when a resident was competent to give consent and the decision for an emergency call was made without resident's involvement. 


\section{$\underline{\text { Physician-related reasons }}$}

Besides staff shortage and lack of time, nurses' behavior was assumed to be a reaction on insufficient cooperation with GPs or other physicians:

[...] there is mostly no communication with the GP [...]. That is also a big problem. He could equally move out to look after his patients, to prescribe something and all residents could remain in the $N H$. $(B 3, F G 2)$

Paramedics reported that physicians were sometimes not able to visit NHRs personally. As a result, nurses were forced to contact the EMS to manage the situation:

[...] the resident does not feel well, and the nursing staff has also other residents to care for. So, they have to find a solution. That means, they call the GP [...] The GP says: 'I cannot move out'. In the next instance they think - 'Okay, if the GP cannot move out. I am afraid of that the resident gets worse and I could get into trouble, therefore I will call the EMS'. $(B 5, F G 1)$

[...] the GP is not available or cannot move out. The GP/OOHC or whoever is responsible in this case. It occurs often enough that the EMS is called as a substitute for the physician. $(B 6, F G 3)$

In many cases physicians could not be reached by telephone. As a consequence, nurses had to decide on their own about patients transfer. This resulted in emergency calls without involvement of the physician.

\section{$\underline{\text { Individual-related reasons }}$}

Apart from the interests of nursing staff and physicians, emergency calls were in some cases initiated because of pressure from family members.

Of course, this is an aspect which we often hear from the nursing staff. 'The relatives put pressure on me if I will not do this or that'. The claims of relatives increased enormous. (B2,FG2)

[...] if the patient says: 'I want to be transported', or if the relative which has the power of attorney says: 'the patient has to be transported', I cannot not transport him. (B5,FG1)

\section{Arrival at nursing home}

Paramedics reported about insufficient handover when arriving in NHs. In some cases, a lot of time was wasted because nobody waited for paramedics and briefed them about reason for calling the EMS:

[...] lacking responsibility. I often experience it when I come to the ward of a NH. It begins, for example, right at the entry. The care manager or anybody else does even not know that the EMS was called, or on which ward we have to get. Of course, this does not always happen, but it gets more frequent. $(B 2, F G 1)$ 
[...] I often notice that the ambulance was called and then there is nobody when we arrive. Then we do not know on which floor and which ward we have to get because nobody is waiting for us [...]. $(B 2, F G 3)$

In their point of view, these situations can also be traced back on staff shortage in NHs. Nevertheless, paramedics criticized nurses' insufficient preparation regarding medical and organizational issues and lack of information:

[...] It is no secret that the ambulance is coming, [...] because normally the nursing staff called us. [...] And then, the patient history and medication plans are not available. [...] This is time extensive, especially in really urgent cases. It would be nice, if we can take a look on resident's prior history, ADs and medication plans at least. In an acute situation it is meaningful to have this information close at hand [...]. (B2,FG3)

In this context, paramedics sometimes experienced communication problems because of language barriers. During handover also ADs were required, but paramedics underlined that they were often missing/not available in NHs:

[...] ADs are a difficult story. Not everyone has one. And if ADs are existent, you have to look for them firstly. And maybe they are not in the NH but at the daughter's home [...] and so on. (B2,FG1)

\section{Transport decision and influencing factors}

When ADs were available, their relevance for transfer decision is low. Instead, paramedics underlined their importance in case of life-threatening situations and for further treatment in the hospital.

Transport decision was accompanied by

ethical concerns, especially when palliative residents in end-of-life situations or residents with dementia were exposed to stressful situations in the ambulance car and overcrowded ED:

[...] we often experienced that. With patients who have dementia or with very old and fearful residents. [...] the transport is horrifying for them. It is shaking in the ambulance and they go to the hospital. I often heard in this context: 'Oh my god, they will never let me out again' [...], they are frightened. (B3, FG1)

We also transport palliative patients which is not necessary. They are going to hospital to die there [...]. They need oxygen, they need calm, they maybe need someone who wet their lips. Analgesics. But they do not need a hospital. (B3,FG2)

In some cases, paramedics did not understand the need for emergency calls. Even if they considered transfers as not necessary because of harmless symptoms, the legal conditions in Germany forced them to transport each resident to the hospital:

We arrive at the $\mathrm{NH}$ and see that the resident is in better hands on-site. But we are no physicians. In Germany just a physician is allowed to make a diagnosis. Therefore, we cannot keep the resident in the NH. $(B 5, F G 1)$ 
We have clear instructions. We have the obligation to transport. We arrive, take the patient with us. This is our job unless the patient refuses. (B6,FG1)

Most paramedics attempted to avoid unnecessary hospital transfers and tried to discuss further treatment. If NHRs were capable and gave written consent to refuse transport, they could remain in $\mathrm{NH}$. In case of dementia, paramedics contacted family members to come to an agreement. They also seek for other alternatives in outpatient care:

[...] just because we leave someone in the $\mathrm{NH}$, it does not mean that we do not send him other medical support. [...] We have also the possibility [...] to call the $\mathrm{OOHC}$, to describe the situation and to hear how they assess it. Or we call the emergency physician [...] to get a solution on-site [...] and to keep the resident in his familiar environment [...]. (B3,FG1)

Even though paramedics feel competent to assess need of a hospital transport, they have no established possibility for reassurance because of physicians' inadequate availability or the infrastructure of ambulance cars (not every ambulance car has a phone on board). Paramedics therefore often felt to operate in legal grey area.

\section{Avoidable hospital transfers}

Being asked which hospital transfers might be avoidable, paramedics primarily referred to clinical symptoms which could be managed in outpatient setting. Lots of unnecessary transports were carried out because of catheter problems. Even though registered nurses in Germany are trained in placing and changing catheter, this did not often happen due to internal instructions and the kind of catheter. When urologists and GPs were not available, nurses were forced to call the EMS. Paramedics reported that these transports were frequent and time and resource intensive. Similar problems were discussed in the context of ruling out fractures after minor trauma (e.g. falls). Further avoidable transfers, for example because of exsiccosis or infections, were based on insufficient time for close monitoring of symptoms:

A patient with a feverish infection or an urinary tract infection does not need to be transferred to hospital by an ambulance. [...] I think [...] that is a combination of [...] medical care, nursing competence and [...] the physicians are not really available and there is a lack of nursing staff resources to monitor the situation closely. (B2,FG3)

\section{Potential interventions to reduce hospital transfers from NHs}

From the perspective of paramedics, avoidable hospital transfers were mainly caused by structural deficiencies and difficult working conditions in NHs. Basically, they saw need for political action regarding staffing ratio and financial compensation which could improve the image of nursing profession. While discussing specific approaches to reduce hospital transfers, the use of more resources in outpatient care was suggested (intersectional management). Paramedics recommended to interconnect phone lines of EMS ("112") and OOHC (in Germany "116 117"). Nurses, who call the EMS in non-serious cases, could be referred to an outpatient physician via telephone. This option was also discussed as an useful resource 
for paramedics if further medical support was needed. Another telephone resource was discussed as a solution to resolve legal uncertainties. Paramedics wished to get reinsurance for need of transport via telephone or telemedicine services:

There is simply an instance missing on which I can reinsure myself. Someone to whom I can say: 'I have this and those things, did I overlook something?' And he says. 'No, you can keep this patient with clear conscience in the $\mathrm{NH}$.' Then we keep him there or 'No, you have to consider this and that, it should be clarified clinically.' (B5,FG1)

And there has to be a point of contact, not for general public but for medical professionals - emergency paramedics, nurses in NHs, nurses in outpatient care [...] who can contact a person who is just responsible to resolve these issues. (B5,FG1)

Further, interventions aiming on working processes and structures in NHs may be helpful. Paramedics discussed in this context the introduction of emergency standards. These would guide nurses in case of NHR deterioration and could improve quality of handover:

Well, it would be nice if they all had the same standards like in emergency care. [...] what to do in case of an emergency and what are the most important things [...]. It does not need to be a big program, they also do not need to learn how to insert a venous access. But they should simply know that an open door is good for us, for example. Or that the bedside table has to be put away. These kinds of stories. (B6,FG1)

[...] to have process descriptions in NHs. When do I have to call the EMS and when not? When do I have to call the OOHC? (B2,FG3)

So far, there is no profession of a NH physician established in Germany. Paramedics appreciated this concept to ensure regular visits in $\mathrm{NHs}$ and to coordinate care of all residents by one physician.

Further approaches to reduce hospital transfers from NHs might aim on qualification and competences. On the one hand, specialization of nurses could be helpful to manage harmless health problems (e.g. catheter problems or signs of exsiccosis) in NHs without involvement of the physician or EMS. In addition, paramedics recommended trainings for nurses regarding emergency standards, relevance of ADs and communication of residents' wishes - maybe integrated in nursing education. To reduce uncertain behavior, information relating to legal and medical aspects of care would be needed. Paramedics considered exchange with nurses as very important to develop two-way understanding for each profession:

[...] it would be certainly helpful for them to do an internship in the EMS. [...] To see which problems we get if documentation in the $\mathrm{NH}$ is not available or incomplete. [...] Maybe they would develop another view if they go with us on the ambulance. Or if we simply get together. (B2,FG2) 


\section{Discussion}

This qualitative study explored experiences of paramedics with hospital transfers from NHs. Our results suggest that structural reasons are relevant contributors to avoidable transfers. Paramedics observed insufficient working conditions and lack of physician's visits in NHs. Medical and organizational handover was often prepared poorly, relevant information for paramedics (e.g. residents' wishes, medication plan) were missing or not complete. Responsible nurses who can give reliable information about resident's condition were perceived as scarce. These challenges after arrival in NHs were also reported in other studies [34, 42]. Jones et al. (2008) showed in this context that nearly $10 \%$ of NHRs were transported to hospital without any documentation [43]. ED physicians considered this insufficient information as difficult for further and rapid treatment in hospital [34].

A study of Murphy-Jones et al. (2016) is so far the only one which examined paramedics' perspectives on transfer process of NHRs, with special focus on end-of-life care situations. The results showed also paramedics' issues to evaluate residents' best interest because of poor documentation in NHs. There were further reports about insufficient nursing staff qualification, and decision-making was perceived as process of negotiation [33]. These findings correspond with the results of our study. In addition, transfer process seems to be influenced by different interests: Murphy-Jones et al. (2016) mentioned nursing staff's lack of willingness to dying residents and therefore preferred hospital treatment [33]. In our study paramedics had similar impressions that nursing staff tried to get rid off NHRs because of high workload and fear of legal consequences. In some cases, also family members have influence on initiation of hospital transports - this was also found out by a recent systematic review of Pulst et al. (2019) [44].

A study of Hauswald (2002) concluded that in contrast to emergency physicians, paramedics cannot safely determine which patients do not require hospital transport or ED care [45]. This conclusion was supported by the paramedics in our focus group. As a result (of not being allowed to make a medical diagnosis) many transfers were carried out because of legal issues.

In some cases, unnecessary utilization of EMS causes ethical considerations. Besides the fact that these transfers might have a negative impact on residents' quality of life, many time and personnel resources were lacking for patients with potential life-threatening symptoms. Paramedics questioned the benefit of hospital transports especially in palliative cases. ADs seemed to have no impact on transfer decisions and are not always available or valid in NHs. This is consistent to the results of Cohen et al. (2017) which illustrated that even "Do-Not-Hospitalize Orders" cannot guarantee treatment in NHs [46]. Issues of unknown resident' wishes were also found in other studies $[47,48]$. Considering a dementia prevalence of 45-62\% among NHRs [49-51], paramedics might be often faced with this problem in transfer process. Therefore, interventions solely aiming to increase ADs among NHRs might not be effective to reduce hospitalization rates. 
Our results suggest that legal uncertainties and structural reasons seem to be a main trigger for unnecessary hospitalizations of NHRs in Germany. Consequently, the majority of these transfers could just be reduced by complex political interventions (e.g. improving nursing staff ratio or legal conditions). Some interventions the paramedics suggested are currently pilot-tested in Germany. For example, some regions interconnected the European emergency call number " 112 " and the number " 116117 " for $0 \mathrm{OHC}$ to coordinate more harmless health problems into outpatient structures [52]. Effects of this intervention are unknown so far, but an evaluation is planned. Another current pilot project aimed on outpatient treatment of non-life threatening patients by specialized community paramedics ("Gemeindenotfallsanitäter") [53]. These paramedics were already dispatched in rescue directing centers and sent out to patients who not require immediate emergency care. In contrast to "regular" paramedics, community paramedics received special training and more medical competences, for example to change catheters. This intervention might have potential to avoid hospital transfers, as already shown in other projects [54]. Effects of the intervention in Germany will be evaluated after the end of the project in 2021.

Besides structural conditions, paramedics saw need for better communication of resident-related information during transfer process. In this context, studies showed that information gaps for NHRs transferred to hospital were common $[43,55]$. Insufficient information was mainly related to reason for transfer, baseline cognitive function and communication ability, vital signs, ADs and medication [55]. ED physicians perceived this insufficient resident information as difficult for further and rapid treatment in hospital [34]. Paramedics within our study discussed in this context a nationwide implementation of obligatory emergency standards in NHs. These could help nursing staff to decide in which cases an emergency call is appropriate and to ensure which processes and information has to be prepared before paramedics arrive in NHs. This idea was also discussed in other studies $[34,56]$. Standardized transfer forms - as one part of these standards - were already developed in some countries [57, 58]. However, use of them is just recommended and not obligatory. For a successful implementation of standards, qualified nursing staff is needed. Paramedics in our study criticized inadequate handovers because nurses were often not prepared and not able to give report about residents pre-existing conditions and symptoms. This perceived lack of qualification could also just be improved by structural interventions. These might include (emergency) trainings for nursing staff and internships in emergency services during nursing education. Further, specialization of nurses is feasible to decrease hospitalization, for example in case of catheter problems or palliative cases. Studies showed in this context, that specialized "nurse practitioner", "physicians assistants" or "advance practice nurses" $[59,60]$ can improve health care and decrease hospitalization of NHRs [61, 62].

\section{Strengths And Limitations}

Research on paramedics' view on transfer process from NHs is scarce. We closed this gap in research and extended evidence on conditions of German health care system. In contrast to the only qualitative study which interviewed paramedics [33], we used a bigger sample to generate data. In addition, we cross-checked focus group findings via participant validation to improve the validity of results. The atmosphere during the focus groups was friendly and open-minded. All participants contributed to a lively 
discussion. We noticed that some participants contributed more than others, but it seemed to be not associated with less working experience. However, no dominant speaker emerged in the groups. The study included participants of different age, sex, regions and sponsorship of EMS to ensure a representative sample. However, the sample might be selective because of snowball sampling in recruitment and voluntary participation. Conditions of EMS organization in the city of Bremen might limit transferability of results to other regions of Germany and to health care systems in other countries.

\section{Conclusions}

Paramedics act as an important linking care profession between $\mathrm{NHs}$ and hospitals. However, research on their experiences with hospital transfers from $\mathrm{NH}$ is limited. To the best of our knowledge, this is the first qualitative study in Germany which provides insights on hospitalization process from paramedics' perspective. Therefore, our study contributed to reduce the gap in this research area. Our results indicate that transfer process of NHRs is complex and influenced by several structural reasons and different interests. Transfers are mainly caused by lack of time for sufficient care in $\mathrm{NHs}$ as well as by legal uncertainties among all involved professional groups. Our results suggest that structures and legal conditions in Germany have to be changed to avoid unnecessary hospital transfers. Short-term interventions which may reduce transfers of NHRs should focus on emergency standards in NHs and improved communication between nursing staff and paramedics, for example in form of specialized education and emergency training.

\section{Abbreviations}

ACS: ambulatory care sensitive

AD: advance directive

COREQ: consolidated criteria for reporting qualitative research

ED: emergency department

EMS: emergency medical services

EMT: emergency medical technician

GP: general practitioner

$\mathrm{NH}$ : nursing home

NHR: nursing home resident

OOHC: out-of-hours medical care

SHI: statutory health insurance 


\section{Declarations}

\section{Ethics approval and consent to participate}

Ethical approval for this study was given by the ethics committee of the local medical association in Bremen, Germany in March 2019 (application number 613/A).

\section{Consent to publish}

The participants of the study gave informed written consent to use data for research and publication.

\section{Availability of data and materials}

The datasets used and analyzed during the current study are available from the corresponding author on reasonable request.

\section{Competing interests}

The authors declare that they have no competing interests.

\section{Funding}

This qualitative study was developed as part of the project 'HOMERN' focusing on hospitalizations and ED visits of nursing home residents in Germany. The project is funded by the Innovation Fund coordinated by the Innovation Committee of the Federal Joint Committee (G-BA) in Germany (grant number: 01VSF16043) which had no influence on the content of the paper and the publication process.

\section{Authors' contribution}

AP and GS developed the concept and design of this qualitative study. Both also recruited participants and took part in the focus groups discussions. Data analysis was performed by AP and was assisted by AF. All authors wrote and reviewed the manuscript critically and approved the final version.

\section{Acknowledgements}


We thank the following members of the research team for commenting on the manuscript: Michael Freitag and Ove Spreckelsen. Special thanks to Insa Seeger for help in recruiting, and Alexandra Zemke and Mareike Würdemann for their support/taking notes during focus group discussions.

\section{References}

1. Gordon AL, Franklin M, Bradshaw L et al. Health status of UK care home residents: a cohort study. Age Ageing. 2014;43(1):97-103.

2. Kojima G. Prevalence of Frailty in Nursing Homes: A Systematic Review and Meta-Analysis. J Am Med Dir Assoc. 2015;16(11):940-5.

3. Hoffmann F, Allers K. Age and sex differences in hospitalisation of nursing home residents: a systematic review. BMJ Open. 2016;6(10):e011912.

4. Ramroth $\mathrm{H}$, Specht-Leible $\mathrm{N}$, Brenner $\mathrm{H}$. Hospitalisations before and after nursing home admission: a retrospective cohort study from Germany. Age Ageing. 2005;34(3):291-4.

5. Allers K, Hoffmann F. Mortality and hospitalization at the end of life in newly admitted nursing home residents with and without dementia. Soc Psychiatry Psychiatr Epidemiol. 2018;53(8):833-9.

6. Gozalo P, Teno JM, Mitchell SL et al. End-of-life transitions among nursing home residents with cognitive issues. N Engl J Med. 2011;365(13):1212-21.

7. Lamberg JL, Person CJ, Kiely DK et al. Decisions to hospitalize nursing home residents dying with advanced dementia. J Am Geriatr Soc. 2005;53(8):1396-401.

8. Menec VH, Nowicki S, Blandford A et al. Hospitalizations at the end of life among long-term care residents. J Gerontol A Biol Sci Med Sci. 2009;64(3):395-402.

9. Miller SC, Dahal R, Lima JC et al. Palliative Care Consultations in Nursing Homes and End-of-Life Hospitalizations. J Pain Symptom Manage. 2016;52(6):878-83.

10. Ramroth $\mathrm{H}$, Specht-Leible $\mathrm{N}$, Konig $\mathrm{HH}$ et al. Hospitalizations during the last months of life of nursing home residents: a retrospective cohort study from Germany. BMC Health Serv Res. 2006;6:70.

11. Frankenhauser-Mannuss J, Goetz K, Scheuer M et al. [Out-of-hours primary care in Germany: general practitioners' views on the current situation]. Gesundheitswesen. 2014;76(7):428-33.

12. Lechleuthner A. Architecture of emergency medical services in Germany. Part I: Integration into the public protection system Notfall Rettungsmed. 2019;22:136-46.

13. Bundesanstalt für Straßenwesen. Einsatzfahrtaufkommen im öffentlichen Rettungsdienst in Prozent (primary source: (primary source: German Federal Statistical Office). In www.gbe-bund.de (keywords: Rettungsdienst $\rightarrow$ art of document: Grafiken, Access date: 09.10.19). , 2011,

14. Carron PN, Dami F, Yersin B et al. Increasing prehospital emergency medical service interventions for nursing home residents. Swiss Med Wkly. 2015;145:w14126.

15. Schmiedel R: Leistungen des Rettungsdienstes 2008/09. Analyse des Leistungsniveaus im Rettungsdienst für die Jahre 2008 und 2009. In: Mensch und Sicherheit Heft M 217. Edited by Bundesanstalt für Straßenwesen. Bergisch Gladbach: Wirtschaftsverlag NW 2011. 
16. Kada O, Janig H, Likar R et al. Reducing Avoidable Hospital Transfers From Nursing Homes in Austria: Project Outline and Baseline Results. Gerontol Geriatr Med. 2017;3:2333721417696671.

17. Lowthian JA, Cameron PA, Stoelwinder JU et al. Increasing utilisation of emergency ambulances. Aust Health Rev. 2011;35(1):63-9.

18. Morley $C$, Unwin M, Peterson GM et al. Emergency department crowding: A systematic review of causes, consequences and solutions. PLoS One. 2018;13(8):e0203316.

19. Trahan LM, Spiers JA, Cummings GG. Decisions to Transfer Nursing Home Residents to Emergency Departments: A Scoping Review of Contributing Factors and Staff Perspectives. Journal of the American Medical Directors Association. 2016;17(11):994-1005.

20. Cardona-Morrell $\mathrm{M}, \mathrm{Kim} \mathrm{JCH}, \mathrm{Brabrand} \mathrm{M}$ et al. What is inappropriate hospital use for elderly people near the end of life? A systematic review. Eur J Intern Med. 2017;42:39-50.

21. Kada O, Brunner E, Likar $R$ et al. [From the nursing home to hospital and back again... A mixed methods study on hospital transfers from nursing homes]. Z Evid Fortbild Qual Gesundhwes. 2011;105(10):714-22.

22. Lemoyne SE, Herbots HH, De Blick D et al. Appropriateness of transferring nursing home residents to emergency departments: a systematic review. BMC Geriatr. 2019;19(1):17.

23. Saliba D, Kington R, Buchanan $\mathrm{J}$ et al. Appropriateness of the decision to transfer nursing facility residents to the hospital. J Am Geriatr Soc. 2000;48(2):154-63.

24. Kapoor A, Field T, Handler S et al. Adverse Events in Long-term Care Residents Transitioning From Hospital Back to Nursing Home. JAMA Intern Med. 2019.

25. Ouslander JG, Weinberg AD, Phillips V. Inappropriate hospitalization of nursing facility residents: a symptom of a sick system of care for frail older people. J Am Geriatr Soc. 2000;48(2):230-1.

26. Becker MA, Boaz TL, Andel $R$ et al. Predictors of preventable nursing home hospitalizations: the role of mental disorders and dementia. Am J Geriatr Psychiatry. 2010;18(6):475-82.

27. McAndrew RM, Grabowski DC, Dangi A et al. Prevalence and patterns of potentially avoidable hospitalizations in the US long-term care setting. Int J Qual Health Care. 2016;28(1):104-9.

28. Wysocki A, Kane RL, Golberstein E et al. The association between long-term care setting and potentially preventable hospitalizations among older dual eligibles. Health Serv Res. 2014;49(3):77897.

29. Harrison JK, McKay IK, Grant P et al. Appropriateness of unscheduled hospital admissions from care homes. Clin Med (Lond). 2016;16(2):103-8.

30. Jensen PM, Fraser F, Shankardass $\mathrm{K}$ et al. Are long-term care residents referred appropriately to hospital emergency departments? Can Fam Physician. 2009;55(5):500-5.

31. Reyniers T, Deliens L, Pasman HR et al. Appropriateness and avoidability of terminal hospital admissions: Results of a survey among family physicians. Palliat Med. 2017;31(5):456-64.

32. Lamb G, Tappen R, Diaz $S$ et al. Avoidability of hospital transfers of nursing home residents: perspectives of frontline staff. J Am Geriatr Soc. 2011;59(9):1665-72. 
33. Murphy-Jones G, Timmons S. Paramedics' experiences of end-of-life care decision making with regard to nursing home residents: an exploration of influential issues and factors. Emerg Med J. 2016;33(10):722-6.

34. Terrell KM, Miller DK. Challenges in transitional care between nursing homes and emergency departments. J Am Med Dir Assoc. 2006;7(8):499-505.

35. Fassmer AM, Hoffmann F. Acute health care services use among nursing home residents in Germany: a comparative analysis of out-of-hours medical care, emergency department visits and acute hospital admissions. Aging Clin Exp Res. 2019.

36. Krueger RA, Casey MA: Focus groups : a practical guide for applied research, vol. 5th edition. Thousand Oaks: SAGE Publications; 2015.

37. Morgan DL: Planning Focus Groups. In: Focus Group Kit 2. Thousand Oaks: SAGE Publications; 1997a.

38. Morgan DL: The Focus Group Guidebook. In: Focus Group Kit 1. Thousand Oaks: SAGE Publications; 1997b.

39. Tong A, Sainsbury P, Craig J. Consolidated criteria for reporting qualitative research (COREQ): a 32item checklist for interviews and focus groups. Int J Qual Health Care. 2007;19(6):349-57.

40. Krueger RA: Developing Questions for Focus Groups. In: Focus Group Kit 2. Thousand Oaks: SAGE Publications; 1997.

41. Elo S, Kyngas H. The qualitative content analysis process. J Adv Nurs. 2008;62(1):107-15.

42. Robinson CA, Bottorff JL, Lilly MB et al. Stakeholder perspectives on transitions of nursing home residents to hospital emergency departments and back in two Canadian provinces. J Aging Stud. 2012;26(4):419-27.

43. Jones JS, Dwyer PR, White LJ et al. Patient transfer from nursing home to emergency department: outcomes and policy implications. Acad Emerg Med. 1997;4(9):908-15.

44. Pulst A, Fassmer AM, Schmiemann G. Experiences and involvement of family members in transfer decisions from nursing home to hospital: a systematic review of qualitative research. BMC Geriatr. 2019;19(1):155.

45. Hauswald M. Can paramedics safely decide which patients do not need ambulance transport or emergency department care? Prehosp Emerg Care. 2002;6(4):383-6.

46. Cohen AB, Knobf MT, Fried TR. Do-Not-Hospitalize Orders in Nursing Homes: "Call the Family Instead of Calling the Ambulance". J Am Geriatr Soc. 2017;65(7):1573-7.

47. Sommer S, Marckmann G, Pentzek $M$ et al. Advance directives in nursing homes: prevalence, validity, significance, and nursing staff adherence. Dtsch Arztebl Int. 2012;109(37):577-83.

48. Tjia J, Dharmawardene M, Givens JL. Advance Directives among Nursing Home Residents with Mild, Moderate, and Advanced Dementia. J Palliat Med. 2018;21(1):16-21.

49. Hoffmann F, Kaduszkiewicz H, Glaeske $\mathrm{G}$ et al. Prevalence of dementia in nursing home and community-dwelling older adults in Germany. Aging Clin Exp Res. 2014;26(5):555-9. 
50. Matthews FE, Dening T, Function UKMRCC et al. Prevalence of dementia in institutional care. Lancet. 2002;360(9328):225-6.

51. Xu S, Jin X, Liu C et al. Investigating the Prevalence of Dementia and Its Associated Risk Factors in a Chinese Nursing Home. J Clin Neurol. 2017;13(1):10-4.

52. Schlingensiepen I. Notrufnummern. Integrierte Leitstelle soll Notfallversorgung richten, 2018; Available from:

https://www.aerztezeitung.de/politik_gesellschaft/berufspolitik/article/957211/notrufnummernintegrierte-leitstelle-soll-notfallversorgung-richten.html

53. Flake F, Schmitt L, Oltmanns W et al. Das Konzept Gemeindenotfallsanitäter/in. Notfall + Rettungsmedizin. 2018;5.

54. Agarwal G, Angeles R, Pirrie M et al. Effectiveness of a community paramedic-led health assessment and education initiative in a seniors' residence building: the Community Health Assessment Program through Emergency Medical Services (CHAP-EMS). BMC Emerg Med. 2017;17(1):8.

55. Cwinn MA, Forster AJ, Cwinn AA et al. Prevalence of information gaps for seniors transferred from nursing homes to the emergency department. CJEM. 2009;11(5):462-71.

56. Arendts G, Howard K. The interface between residential aged care and the emergency department: a systematic review. Age Ageing. 2010;39(3):306-12.

57. Association AMD. Transitions of Care in the Long-Term Care Continuum. Practice Guideline, 2010, Available from: https://qioprogram.org/sites/default/files/Transitions_of_Care_in_LTC.pdf,

58. Tsai HH, Tsai YF. Development, validation and testing of a nursing home to emergency room transfer checklist. J Clin Nurs. 2018;27(1-2):115-22.

59. Intrator O, Zinn J, Mor V. Nursing home characteristics and potentially preventable hospitalizations of long-stay residents. J Am Geriatr Soc. 2004;52(10):1730-6.

60. Kane RL, Keckhafer G, Flood S et al. The effect of Evercare on hospital use. J Am Geriatr Soc. 2003;51(10):1427-34.

61. Bakerjian D. Care of nursing home residents by advanced practice nurses. A review of the literature. Res Gerontol Nurs. 2008;1(3):177-85.

62. Christian R, Baker K. Effectiveness of Nurse Practitioners in nursing homes: a systematic review. JBI Libr Syst Rev. 2009;7(30):1333-52.

\section{Tables}

Tab. 1: Description of focus group members 


\begin{tabular}{|c|c|c|c|c|c|c|}
\hline $\begin{array}{l}\text { Focus } \\
\text { group }\end{array}$ & $\begin{array}{l}\text { Participants } \\
\text { (n) }\end{array}$ & Sex & $\begin{array}{l}\text { Age } \\
\text { (years) }\end{array}$ & Profession & $\begin{array}{l}\text { Working experience } \\
\text { (years) }\end{array}$ & Working area \\
\hline 1 & 7 & $\begin{array}{l}\text { Male } \\
\mathrm{n}=6 \\
\text { Female } \\
\mathrm{n}=1\end{array}$ & $\begin{array}{l}\text { Range: } \\
\text { 21-44 } \\
\text { Mean: } 31\end{array}$ & $\begin{array}{l}\text { EMT } \mathrm{n}=2 \\
\text { Paramedic } \mathrm{n}=2 \\
\text { Emergency } \\
\text { paramedic } \mathrm{n}=3\end{array}$ & $\begin{array}{l}\text { Range: 3-23 } \\
\text { Mean: } 9\end{array}$ & $\begin{array}{l}\text { Urban } \mathrm{n}=4 \\
\text { Semi- } \\
\text { urban/rural } \mathrm{n}=3\end{array}$ \\
\hline 2 & 5 & $\begin{array}{l}\text { Male } \\
\mathrm{n}=4 \\
\text { Female } \\
\mathrm{n}=1\end{array}$ & $\begin{array}{l}\text { Range: } \\
26-34 \\
\text { Mean: } 29\end{array}$ & $\begin{array}{l}\text { Paramedic } n=1 \\
\text { Emergency } \\
\text { paramedic } n=4\end{array}$ & $\begin{array}{l}\text { Range: } 2-14 \\
\text { Mean: } 8\end{array}$ & $\begin{array}{l}\text { Urban } \mathrm{n}=4 \\
\text { Semi- } \\
\text { urban/rural } \mathrm{n}=1\end{array}$ \\
\hline 3 & 6 & $\begin{array}{l}\text { Male } \\
\mathrm{n}=5 \\
\text { Female } \\
\mathrm{n}=1\end{array}$ & $\begin{array}{l}\text { Range: } \\
23-55 \\
\text { Mean: } 38\end{array}$ & $\begin{array}{l}\text { EMT } \mathrm{n}=2 \\
\text { Paramedic } \mathrm{n}=1 \\
\text { Emergency } \\
\text { paramedic } \mathrm{n}=3\end{array}$ & $\begin{array}{l}\text { Range: } 1-29 \\
\text { Mean: } 13\end{array}$ & $\begin{array}{l}\text { Urban } n=3 \\
\text { Semi- } \\
\text { urban/rural } n=3\end{array}$ \\
\hline Total & 18 & $\begin{array}{l}\text { Male } \\
\mathrm{n}=15 \\
\text { Female } \\
\mathrm{n}=3\end{array}$ & $\begin{array}{l}\text { Range: } \\
21-55 \\
\text { Mean: } 33\end{array}$ & $\begin{array}{l}\text { EMT } n=4 \\
\text { Paramedic } n=4 \\
\text { Emergency } \\
\text { paramedic } n=10\end{array}$ & $\begin{array}{l}\text { Range: } 1-23 \\
\text { Mean: } 10\end{array}$ & $\begin{array}{l}\text { Urban } \mathrm{n}=11 \\
\text { Semi- } \\
\text { urban/rural } \mathrm{n}=7\end{array}$ \\
\hline
\end{tabular}

\section{Figures}

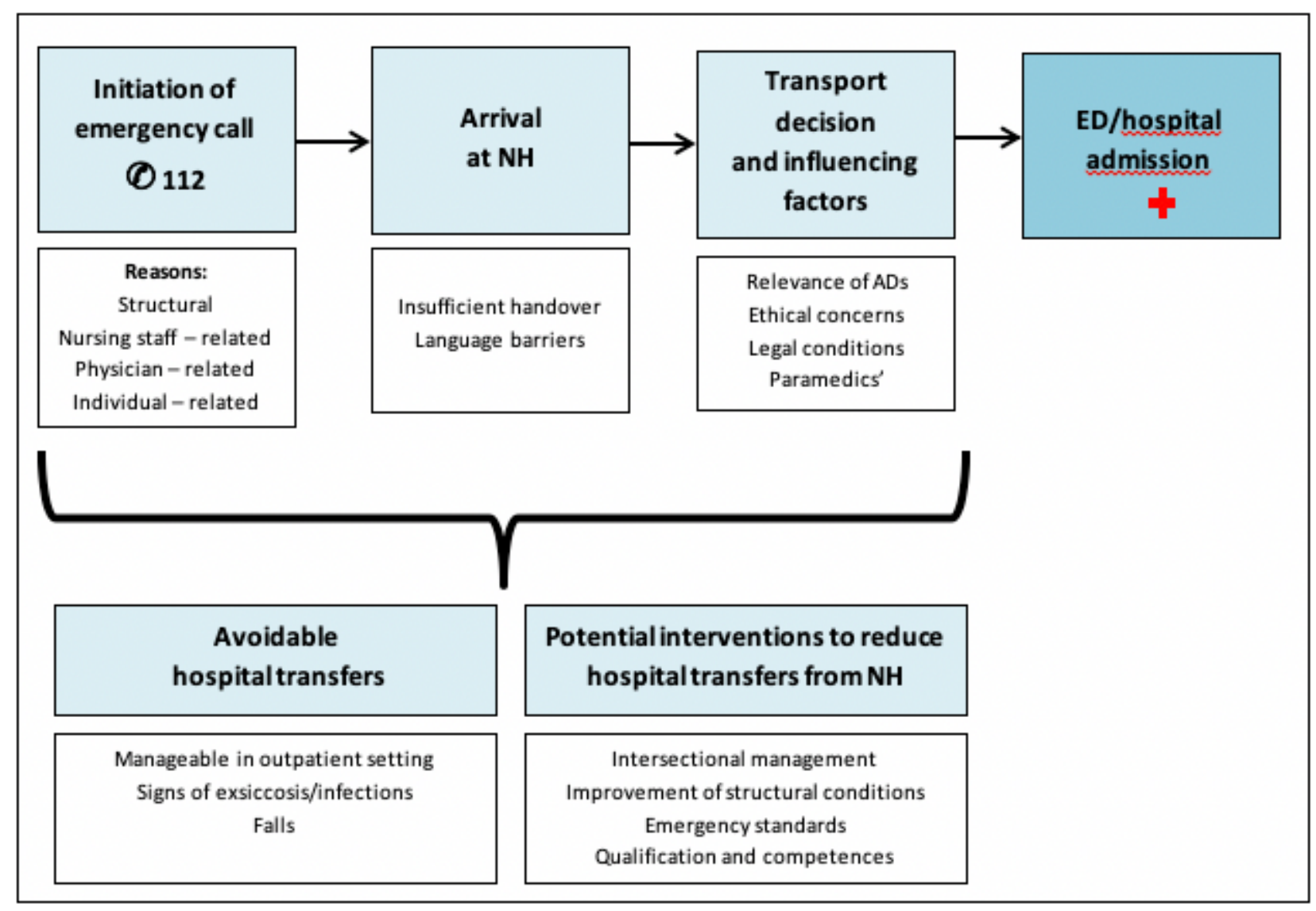

Figure 1 
Main themes in hospital transfer process: Overview of categories and subcategories

\section{Supplementary Files}

This is a list of supplementary files associated with this preprint. Click to download.

- Additionalfilel.docx

- COREQchecklistPulstetal..doc 